Thorax (1965), 20, 135.

\title{
Significance of changes in the pulmonary diffusing capacity in mitral stenosis
}

\author{
CLIVE P. ABER ${ }^{1}$ A N D J A. CAM P B E L L \\ From the Liverpool Thoracic Surgical Centre and the Department of Pathology, Broadgreen Hospital, \\ Liverpool
}

The pulmonary vascular consequences of chronic mitral valve obstruction have received considerable attention in recent years (Gough, 1955; Evans and Short, 1957; Harrison, 1958). Obliterative lesions involving initially the small peripheral branches of the pulmonary artery which supply the lower rather than the upper lobes has been a common finding in most of these studies, although the more severe and longstanding the valvular stenosis, the more advanced and widespread is this type of arterial damage. Angiographic and isotope observations have also revealed a characteristic early redistribution of blood flow through the lungs in mitral stenosis, which appears to reflect this vascular damage with considerable accuracy. Initially there is abolition of the normal blood flow difference between the upper and lower zones, with subsequent reversal of the normal flow pattern as the vascular damage advances (Davies, Goodwin, Steiner, and Van Leuven, 1953 ; Evans and Short, 1957 ; Simon, 1958 ; Dollery and West, 1960 ; Steiner, Harrison, and Goodwin, 1961). In contrast, gross abnormalities of pulmonary function are relatively uncommon in mitral stenosis, although moderate changes in lung volumes, ventilatory capacity, and gas distribution have been reported (Carroll, Cohn, and Riley, 1953 ; Frank, Cugell, Gaensler, and Ellis, 1953 ; McIlroy and Apthorp, 1958; Friedman, de J. Macias, and Yu, 1959; Turino and Fishman, 1959 ; Aber, 1963 ; Arnott, 1963). Severe impairment of diffusion, on the other hand, has frequently been observed in patients disabled with this type of heart lesion (Curti, Cohen, Castleman, Scannell, Friedlich, and Myers, 1953 ; Williams, 1953 ; Marshall, McIlroy, and Christie, 1954 ; Auchincloss, Gilbert, and Eich, 1959; Aber, 1962 ; Reid and Stevenson, 1963), and several workers have shown that in general the higher the pulmonary artery pressure and pulmonary

\footnotetext{
2 Present address : Liverpool Royal Infirmary
}

vascular resistance the lower the pulmonary diffusing capacity (Carroll et al., 1953 ; Auchincloss et al., 1959; Aber, 1962; Reid and Stevenson, 1963). However, exceptions to this relationship are fairly frequent.

Since it is now generally agreed that in the presence of generalized lung damage, whether due to primarily parenchymal or vascular disease, impairment of pulmonary diffusion denotes a disturbance of the ventilation:perfusion balance throughout the lungs rather than a specific 'block' to gaseous exchange at the alveolar capillary membrane (Williams and Hugh-Jones, 1960; Finley, Swenson, and Comroe, 1962), it seemed worth while re-examining this aspect of pulmonary function in mitral stenosis in an attempt to relate observed disturbances in diffusion to both the haemodynamic changes and pulmonary vascular damage of this form of heart disease.

\section{MATERIAL AND METHODS}

Seventy-nine patients were included in this investigation. They were selected from the patients with chronic rheumatic mitral stenosis, who presented for mitral valvotomy at the Liverpool Thoracic Surgical and the Liverpool Cardiac Centres.

All patients had dominant mitral stenosis as determined by pre-operative clinical, radiological, electrocardiographic, and phonocardiographic observations. The final evaluation of the mitral valve lesion was made at cardiotomy. Patients with evidence of other significant valvular heart lesions, systemic hypertension, primary pulmonary disease, or anaemia were excluded.

CLINICAL DATA

Age and sex There were 13 men and 66 women. The average age of the men was 45 years (range 22 to 56 years) and of the women 40.5 years (range 20 to 63 years).

Functional disability The patients were graded according to their pre-operative exercise tolerance. as 
suggested by the New York Heart Association Classification (1945). Each was then placed in one of four groups (I to IV).

Group I: Undue breathlessness on severe exertion. Patients in this group lead virtually normal lives but cannot keep up with their fellows during physical pursuits.

Group II: Breathlessness on moderate exertion. Patients in this group cannot hurry, although they are able to walk a mile or more on the flat at their own pace. Hills and stairs can only be managed slowly.

Group III: Serious incapacity that interferes with daily routine. Only light or sedentary work is possible for the men, and the women can only manage light housework and shopping with difficulty. Frequent rests are needed on stairs and inclines.

Group IV: Complete incapacity. Housework and shopping are impossible and the least physical effort causes great fatigue and breathlessness.

There were five patients (two men and three women) in group I; 35 patients (six men and 29 women) in group II ; 33 patients (four men and 29 women) in group III ; and six patients (one man and five women) in group IV.

PHYSIOLOGICAL METHOdS All physiological measurements were made after the patients had been rendered free from both congestive cardiac failure and clinical pulmonary congestion, when these were present on admission to hospital. Each investigation was carried out within 14 days of the proposed mitral valvotomy.

PULMONARY FUNCTION TESTS The pulmonary diffusing capacity was estimated by the single-breath carbon monoxide method of Ogilvie, Forster, Blakemore, and Morton (1957), and the predicted normal values for the pulmonary diffusing capacity for carbon monoxide were calculated from their regression formula.

The residual volume was determined by a closedcircuit helium dilution method (Weiner and Cooper, 1956).

All measurements were made by one of the authors (C. P. A.) with the patients at rest in the sitting position.

Right heart catheterization was performed in a conventional manner (Hellems, Haynes, Dexter, and Kinney, 1948) in 30 patients, to determine cardiac output (pulmonary blood flow) and pulmonary vascular resistance (P.V.R.). All pressure curves were recorded through either a Sanborn strain-gauge transducer or a Sanborn electromanometer on a directwriting Twin Viso recorder. Mean pressures were determined by electrical or planimetric integration.

Pathological measurements Small wedge biopsy specimens were obtained from well inflated anterior portions of 62 lingulae at thoracotomy. Each was placed directly into $10 \%$ formalin fixative and embedded in paraffin wax. Sections were cut and stained with haematoxylin and eosin for general examination, and with Weigert's elastic stain, counterstained with Van Gieson's connective tissue stain, for measurements on the pulmonary muscular arteries and arterioles.

Pulmonary muscular arteries were vessels of dia- के meter range 100-1,000 $\mu$, having a muscular media $\vec{\circ}$ lying between intima and adventitia and bounded by internal and external elastic laminae (Fig. 3a). Pulmonary arterioles were vessels of $100 \mu$ or less in external diameter, having a single elastic membrane and usually no muscular component, or at the most a single layer of muscle fibre in their walls (Fig. 4a).

Comparable control material was obtained from 26 patients of ages ranging from 23 to 69 years, who had died without evidence of either cardiac or respiratory disease.

All sections were examined and assessed by both authors independently. When there was disagreement regarding the evaluation of any section, it was reviewed by both authors, and a final grading was established.

The following quantitative microscopic observations were made on each biopsy specimen:

THICKNESS OF MEDIA IN SMALL PULMONARY MUSCULAR ARTERIES This was expressed as a percentage of the external diameter of the vessel by the method of Heath and Whitaker (1955) (Fig. 1). The media (M)

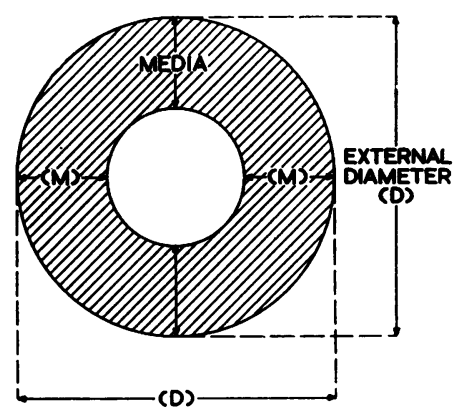

FIG. 1. Measurement of medial thickness $(M)$ as a percentage of the external diameter $(D)$ of the pulmonary $N$ muscular arteries.

of each vessel in the section was measured at the four quadrants, and the average of the values obtained was taken as the mean thickness of the media.

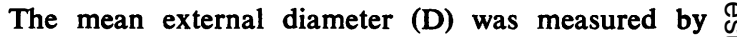
taking the average of two external diameters at right angles to each other. The mean value of the thickness of the media was then expressed as a percentage of the mean value of the external diameter.

LUMEN TO WALL RATIO The mean value for this ratio was obtained for both the small pulmonary muscular arteries (L:Wa) and the pulmonary 


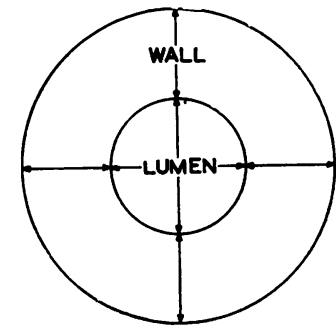

FIG. 2. Measurement of the lumen-to-wall ratios of the pulmonary muscular arteries $(L: W a)$ and arterioles $(L: W b)$.

arterioles (L:Wb) in each section, using the method described by Kernohan, Anderson, and Keith (1929) (Fig. 2). The thickness of the respective vessel wall (W), exclusive of the adventitia, was measured at the four quadrants. The average of these four values was then taken as the wall thickness of a given vessel. The lumen (L) was measured by taking the average of two internal diameters at right angles to each other.

SEVERITY OF INTIMAL THICKENING This was evaluated for small pulmonary muscular arteries and arterioles separately, according to the scheme presented in Table I. Marks were awarded as indicated (Figs. 3 and 4).

TABLE I

ASSESSMENT OF THE DEGREE OF INTIMAL THICKENING IN THE PULMONARY MUSCULAR ARTERIES AND ARTERIOLES attempted between measurements and observations on these and those made on biopsy material collected from patients in the other three functional groups.

\section{RESULTS}

PULMONARY DIFFUSING CAPACITY The mean value of the pulmonary diffusing capacity decreased as the degree of functional disability increased (Fig. 5). There were six patients (7.6\%) with diffusing capacities of $120 \%$ or more of the predicted normal value. Two of these patients were in group I and four were in group II. Impairment of diffusion to below $70 \%$ of normal, on the other hand, was found in 23 patients (29\%), most of whom were in group III. Moderately severe reduction in diffusion (less than $60 \%$ predicted) was seen in 11 patients, seven ( $21 \%$ ) from group III and four (66\%) from group IV. Marked diffusion difficulty, expressed by values of less than $50 \%$ of predicted normal, was seen in only seven patients $(9.0 \%)$, all of whom were in either group III or group IV (Table II).

TABLE II

PULMONARY DIFFUSING CAPACITY RELATIVE TO FUNCTIONAL INCAPACITY IN MITRAL STENOSIS

\begin{tabular}{|c|c|c|c|c|}
\hline \multirow{2}{*}{$\begin{array}{c}\text { DL } \\
(\% \text { pred. })\end{array}$} & \multicolumn{4}{|c|}{ Functional Status } \\
\hline & $\begin{array}{c}\mathrm{I} \\
\text { (5 patients) }\end{array}$ & $\begin{array}{l}\text { II } \\
\text { (35 patients) }\end{array}$ & $\mid \begin{array}{c}\text { III } \\
\text { (33 patients) }\end{array}$ & $\begin{array}{l}\text { IV } \\
\text { (6 patients) }\end{array}$ \\
\hline $\begin{array}{c}120 \text { or }> \\
70 \text { or }< \\
60 \text { or }< \\
50 \text { or }<\end{array}$ & $\begin{array}{c}2(40 \%) \\
1(20 \%) \\
- \\
-\end{array}$ & $\begin{array}{c}4(11 \%) \\
6(17 \%) \\
-\end{array}$ & $\begin{array}{l}12(\overline{36 \cdot 5} \%) \\
7(21 \cdot 2 \%) \\
4(12 \cdot 2 \%)\end{array}$ & $\begin{array}{l}4(\overline{66 \cdot 6 \%}) \\
4(66 \cdot 6 \%) \\
3(50 \%)\end{array}$ \\
\hline
\end{tabular}

Patients who had never experienced symptoms of pulmonary venous hypertension (27 patients) and those with mild symptoms of this nature $(30$ patients) had similar diffusing capacities. In the presence of a history of severe recent orthopnoea or paroxysmal nocturnal dyspnoea ( 22 patients), on the other hand, the diffusing capacity was frequently severely reduced (Fig. 6).

\section{PULMONARY VASCULAR DAMAGE}

Pulmonary muscular arteries Despite the relatively small variation between the three functional groups in respect of the measurement of medial thickness $(M / D \%)$, in each group it was considerably higher than the mean control value of $5.2 \%$ (range 3.2 to $6.8 \%$ ) and increased as the functional disability became greater. Medial thickening of $10 \%$ or more occurred in $29(47 \%)$ of the 62 biopsies (Table III). Only two biopsies, both from patients in group III, showed medial 
(a)

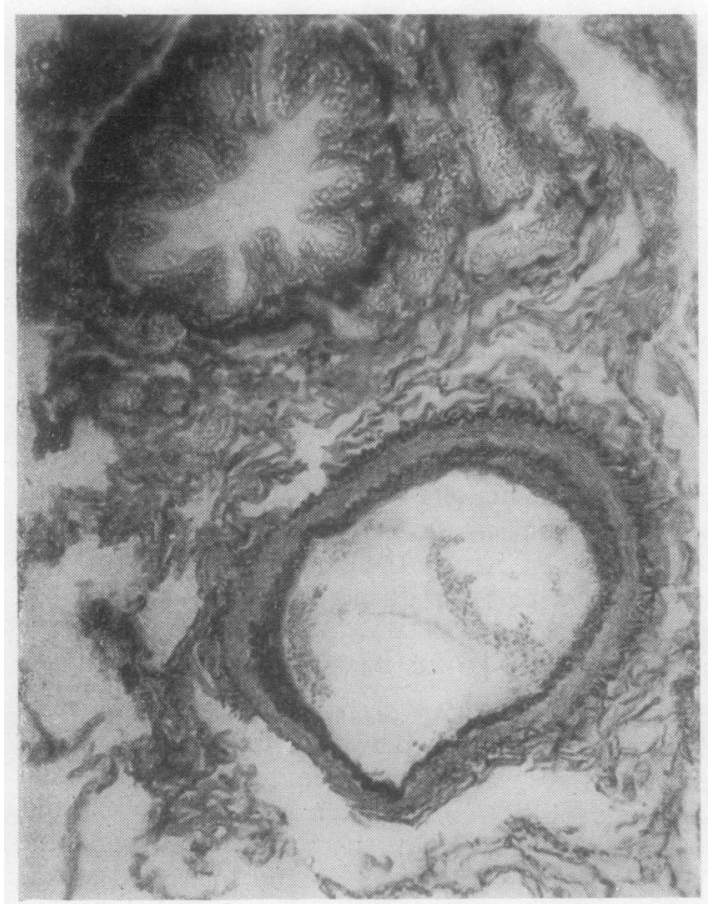

(b)

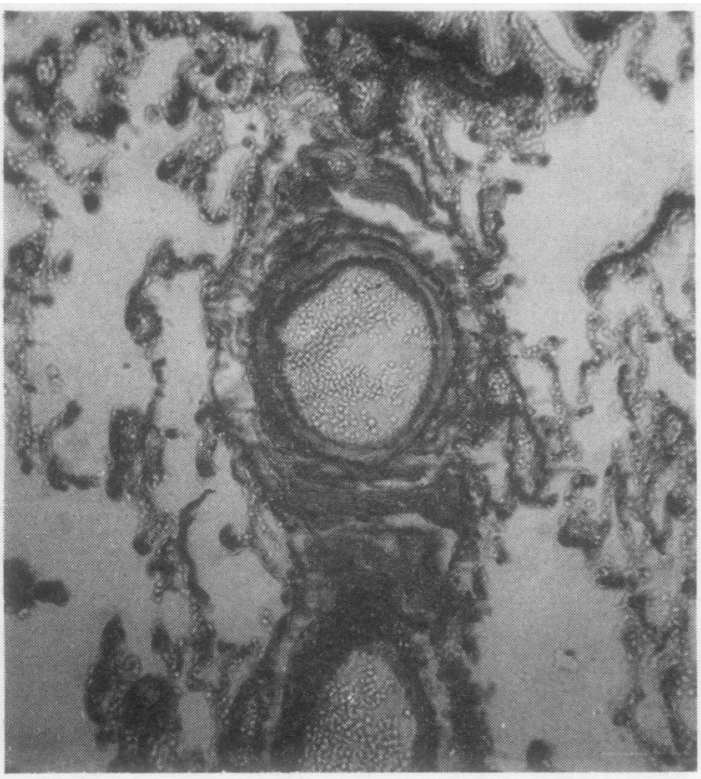

(1)

FIG. 3. (a) Normal pulmonary muscular artery; (b) grade 1, in a pulmonary muscular artery. Weigert's elastic and van Gieson stain, $\times 75$.

(c)

(d)
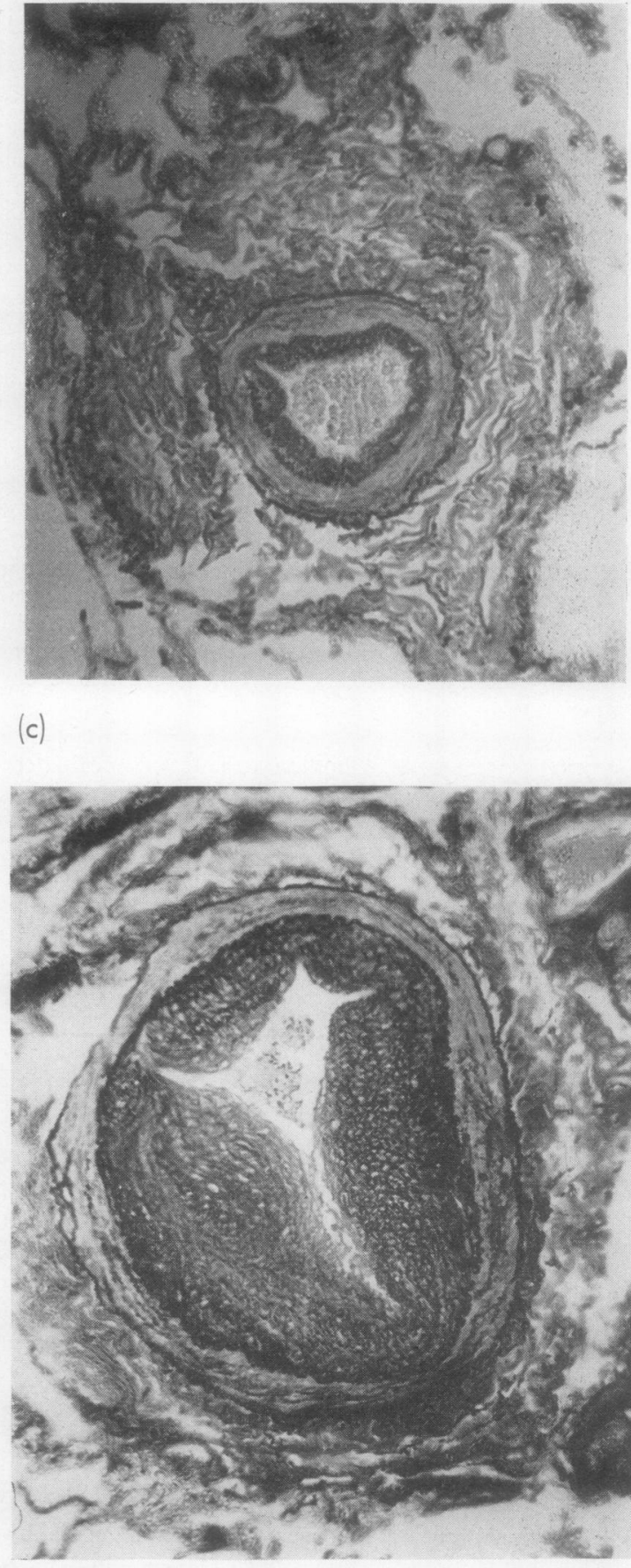

年

$\sum^{\circ}$

ఖ

8 


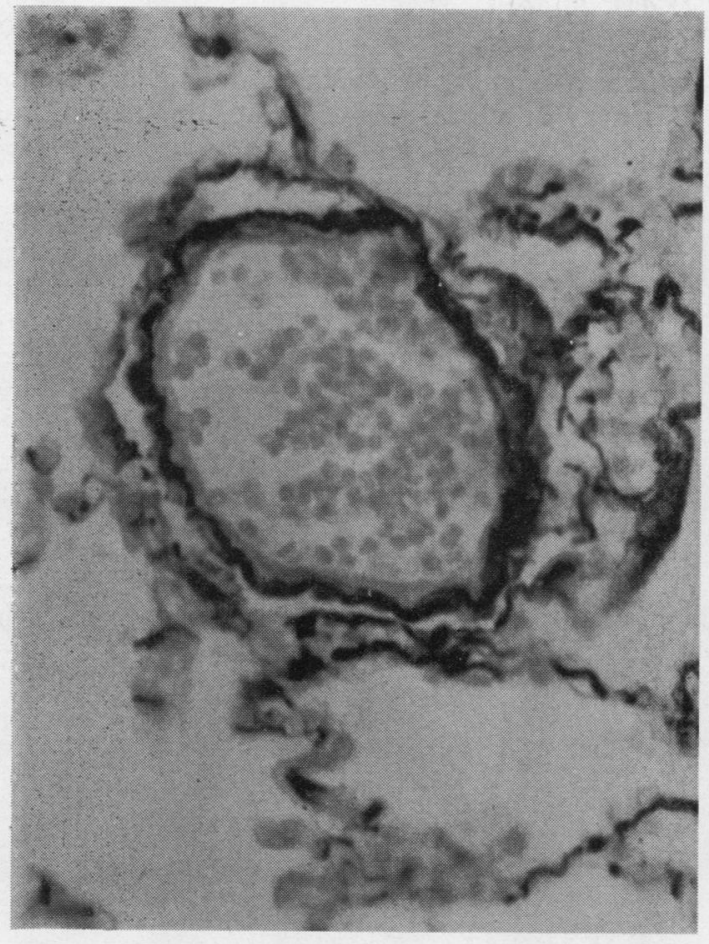

(a)

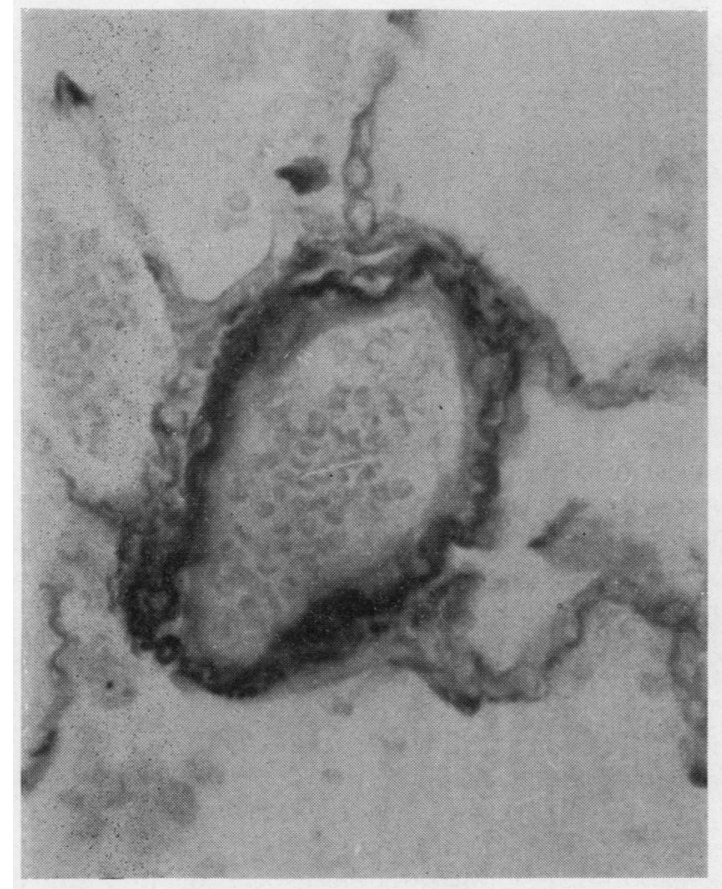

(b)

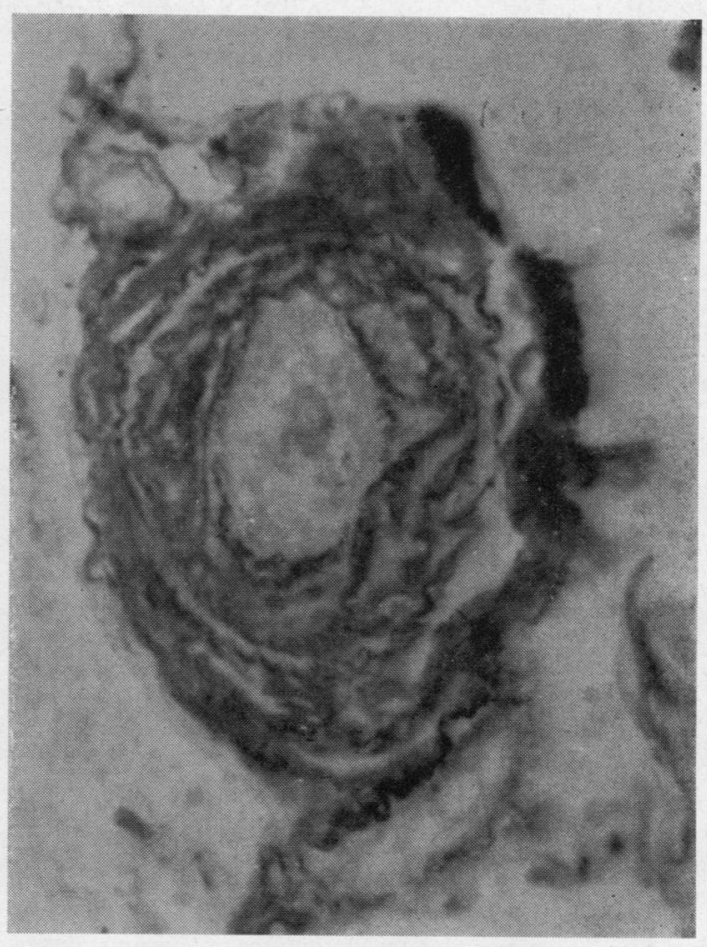

(c)

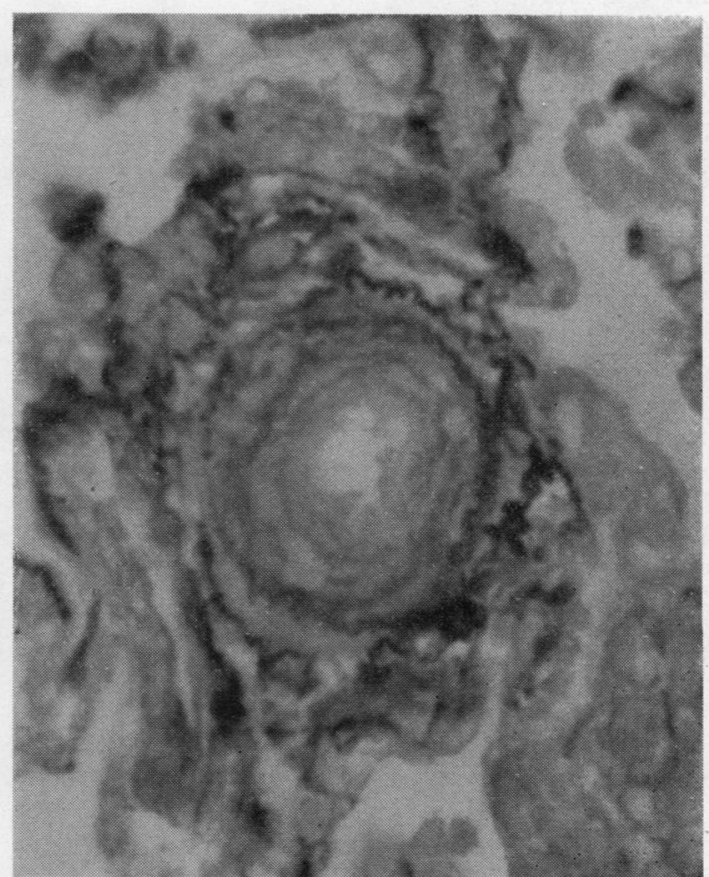

(d)

FIG. 4. (a) Normal pulmonary arteriole; (b) grade 1, (c) grade 2, and (d) grade 3 intimal thickening in a pulmonary arteriole. Weigert's elastic and van Gieson stain, $\times 265$. 


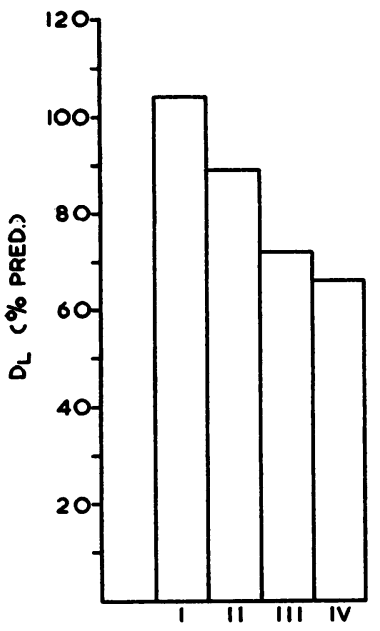

FUNCTIONAL GROUPS

FIG. 5

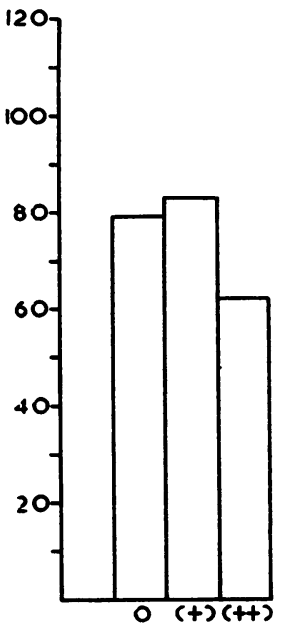

ORTH./P.N.D.

FIG. 6

FIG. 5. Relationship between the pulmonary diffusing capacity $(D \mathrm{~L})$ and functional incapacity $(I-I V)$ in mitral stenosis.

FIG. 6. Relationship between pulmonary venous hypertensive symptoms (Orth./P.N.D.) and the pulmonary diffusing capacity $(D \mathrm{~L})$ in mitral stenosis. $\bigcirc$ no history of orthopnoea or paroxysmal nocturnal dyspnoea (27 patients); + mild symptoms of orthopnoea or paroxysmal nocturnal dyspnoea (30 patients); + + severe symptoms of orthopnoea or paroxysmal nocturnal dyspnoea (22 patients).

thickening greater than $15 \%$ of the external diameter.

In 16 biopsies ( $26 \%$ ), the lumen to wall ratio (L:Wa) was within the normal range $(7 \cdot 2: 1$ to 26.1:1). Ten of these came from patients in group II and six from patients in group III. A ratio of $4: 1$ or less, on the other hand, indicating moderately severe arterial narrowing, was frequent in the sections from group III and group IV (Table III).

Pulmonary arterioles Even in the biopsies from patients with relatively little disability (group II), the lumen to wall ratio $(\mathrm{L}: \mathrm{Wb})$ was frequently well below the lower limit of the normal range (6.6:1 to 11.8:1), 19 sections from this group (68\%) having ratios of less than $6 \cdot 6: 1$. Extreme narrowing of the lumen, as evidenced by a ratio of $3: 1$ or less, was observed only once in the biopsies from group II, but was common in those from group III (42\%) and group IV (33\%) (Table III).

Intimal thickening Significant intimal thickening (3 marks or more) was not seen in the control sections.

In the biopsy sections this type of lesion was again more obvious as the functional disability became greater and was nearly always of equal magnitude in both the muscular arteries and arterioles in any section. Nearly half the biopsies from patients in groups III and IV (47\%) gained 3 marks or more (Table III). However, there were four biopsies from patients in group III which showed no intimal damage despite marked medial thickening in the small muscular arteries (Fig. 7).

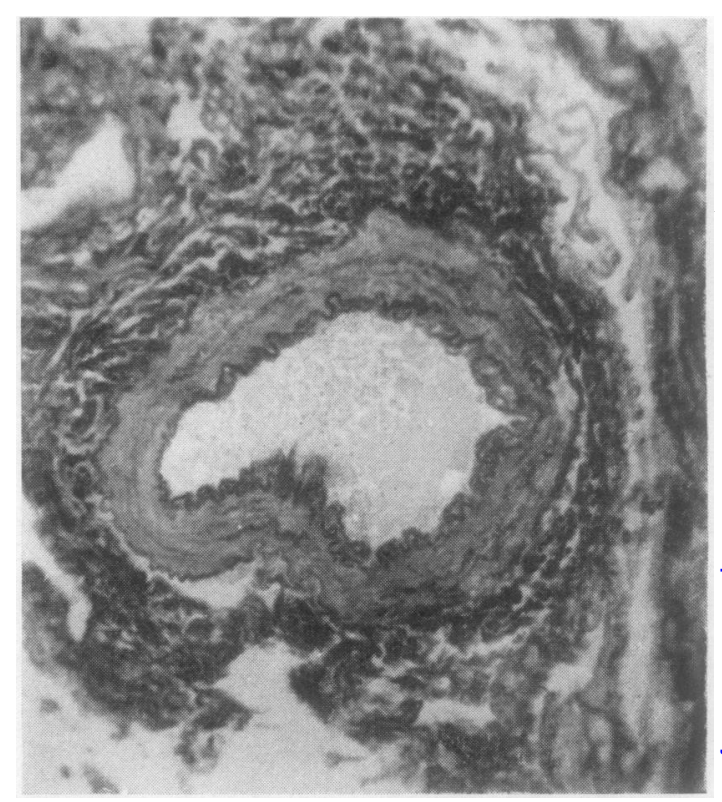

FIG. 7. A muscular pulmonary artery showing considerable medial thickening but no intimal damage. Weigert's elastic and van Gieson stain, $\times 65$.

RELATIONSHIP BETWEEN DIFFUSING CAPACITY AND HAEMODYNAMIC CHANGES AND OBLITERATIVE $N$ VASCUlaR DAMAGE No significant relationship was observed between cardiac output (pulmonary blood flow) and diffusion. However, an interesting relationship was noted between the pulmonary vascular resistance and the diffusing capacity. Whereas the latter was less than $60 \%$ of predicted normal in nine of the 13 patients with a resistance of 5 units or more (Fig. 8), there were four patients with very high pulmonary vascular resistances yet normal diffusing capacities. These four exceptions demonstrate an aspect of this study which will be discussed later. 
TABLE III

PULMONARY VASCULAR DAMAGE RELATIVE TO FUNCTIONAL INCAPACITY IN MITRAL STENOSIS

\begin{tabular}{|c|c|c|c|c|c|}
\hline & \multirow{3}{*}{\begin{tabular}{|c|}
$\begin{array}{c}\text { CONTROL GROUP } \\
\text { (26 SECTIONS) }\end{array}$ \\
$\begin{array}{c}5.2 \\
(3.2-6.8)\end{array}$ \\
\end{tabular}} & \multicolumn{3}{|c|}{ FUNCTIONAL STATUS } \\
\hline & & & \multicolumn{2}{|c|}{\begin{tabular}{c|c} 
GROUP II & GROUP III \\
(28 BIOPSIES) & (26 BIOPSIES)
\end{tabular}} & \multirow{2}{*}{$\begin{array}{c}\text { GROUP IV } \\
\text { (6 BIOPSIES) } \\
\begin{array}{c}11 \cdot 3 \\
(6.7-14 \cdot 9)\end{array}\end{array}$} \\
\hline \multirow{6}{*}{$\begin{array}{l}\text { PULMONARY } \\
\text { MUSCULAR } \\
\text { ARTERIES }\end{array}$} & $\begin{array}{l}\text { MEAN M/D\%\% } \\
\text { (RANGE) }\end{array}$ & & $(5 \cdot 2-12 \cdot 5)$ & $\begin{array}{c}10 \cdot 9 \\
(5 \cdot 8-18 \cdot 5)\end{array}$ & \\
\hline & $M / D \%>10 \%$ & 0 & $10(36 \%)$ & $14(54 \%)$ & $5(85 \%)$ \\
\hline & & & & & \\
\hline & $\begin{array}{l}\text { MEAN L:W(a) } \\
\text { (RANGE) }\end{array}$ & $\begin{array}{c}16 \cdot 2: 1 \\
(7 \cdot 2-26: 1: 1)\end{array}$ & $\begin{array}{c}6 \cdot 7: 1 \\
(2 \cdot 8-12 \cdot 2: 1)\end{array}$ & $\begin{array}{c}4 \cdot 5: 1 \\
(0.5-13.7: 1)\end{array}$ & $\begin{array}{c}3 \cdot 5: 1 \\
(2 \cdot 0-4 \cdot 0: 1)\end{array}$ \\
\hline & $L: W(0)<4 \cdot 0: I$ & 0 & $9(32 \%)$ & $15 \mathrm{C} 58 \%$ & $6(100 \%)$ \\
\hline & & & & (O) & (0) \\
\hline \multirow{7}{*}{$\begin{array}{l}\text { PULMONARY } \\
\text { ARTERIOLES }\end{array}$} & $\begin{array}{l}\text { MEAN L:W W (b) } \\
\text { (RANGE) }\end{array}$ & $\begin{array}{c}8 \cdot 8: 1 \\
(6 \cdot 6-11 \cdot 8: 1)\end{array}$ & $\begin{array}{c}6 \cdot 3: 1 \\
(2 \cdot 6-12 \cdot 6: 1)\end{array}$ & $\begin{array}{c}4 \cdot 0: 1 \\
(1 \cdot 7-9 \cdot 1: 1) \\
\end{array}$ & $\begin{array}{c}3 \cdot 3: 1 \\
(1 \cdot 9-4 \cdot 8: 1)\end{array}$ \\
\hline & $L: W(b)<6.6: 1$ & 0 & $19(68 \%)$ & $19(73 \%)$ & $6(100 \%)$ \\
\hline & $\mathrm{L}: W(b)<3 \cdot 0: 1$ & 0 & $1(3.5 \%)$ & $11(42 \%)$ & $2(33.3 \%)$ \\
\hline & $\begin{array}{l}\text { INTIMALC(mks) } \\
\text { THICKENING } \\
\text { (RANGE) }\end{array}$ & $\begin{array}{c}0 \\
(0-1)\end{array}$ & $\begin{array}{c}1.4 \\
(0-4.5)\end{array}$ & $\begin{array}{c}2 \cdot 7 \\
(0-5)\end{array}$ & $\begin{array}{c}3 \cdot 4 \\
(2-5)\end{array}$ \\
\hline & 2 MARKS OR MORE & 0 & $5(18 \%)$ & $14(54 \%)$ & $6(100 \%)$ \\
\hline & 4 MARKS OR MORE & 0 & $2(7.1 \%)$ & $10(38 \%)$ & $3(50 \%)$ \\
\hline & & & (0) & (0) & 0 \\
\hline
\end{tabular}

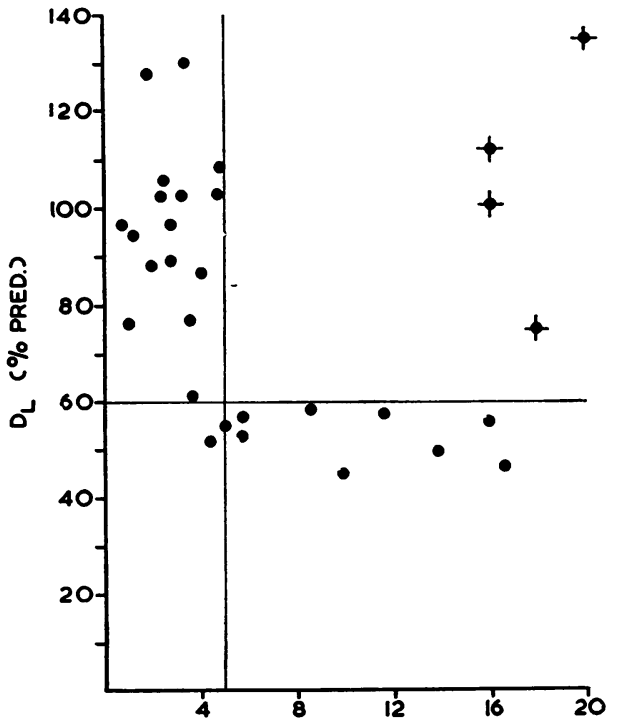

P.V.R. (UNITS)

FIG. 8. Relationship between pulmonary diffusing capacity (DL) and pulmonary vascular resistance (P.V.R.) in mitral stenosis. + patients with high pulmonary vascular resistances but normal diffusing capacities; patients in the study.
No definite correlation was established between diffusion and the vascular wall measurements $(\mathrm{M} / \mathrm{D} \%, \mathrm{~L}: \mathrm{Wa}$, and $\mathrm{L}: \mathrm{Wb})$, although impairment of diffusion to levels below $60 \%$ occurred in a third of the patients in whose biopsies the $L: W a$ ratio was less than $5 \cdot 7: 1$, and in nearly half $(43 \%)$ of those whose $L: W b$ ratio was less than 5:1 (Figs 9 and 10).

A better correlation was observed between the diffusing capacity and intimal thickening in the peripheral branches of the pulmonary artery (Fig. 11).

There were three patients, however, with considerable intimal thickening in their biopsies who had diffusing capacities greater than $70 \%$ of predicted normal, and four patients with minimal intimal damage yet pulmonary diffusing capacities between 60 and $70 \%$ of predicted normal. The 11 patients with diffusing capacities less than $60 \%$ of predicted normal had severe intimal changes in their biopsies.

RELATIONSHIP BETWEEN PULMONARY VASCULAR RESISTANCE AND SEVERITY OF THE INTIMAL CHANGES When the pulmonary vascular resistance was 5 units or more, intimal thickening was usually appreciable (Fig. 12). However, here again 


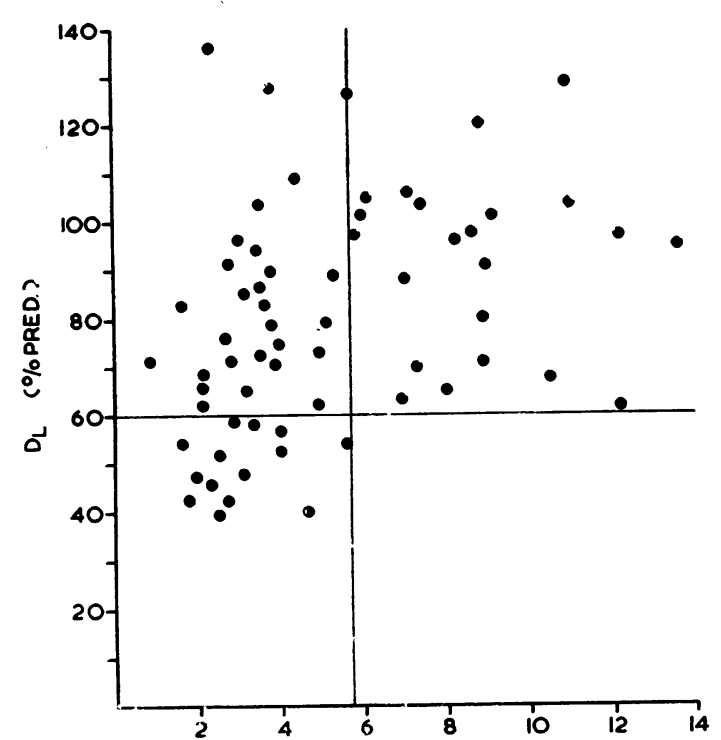

$L: W(a)$

FIG. 9. Relationship between pulmonary diffusing capacity $\left(D_{\mathrm{L}}\right)$ and lumen-to-wall ratio of the pulmonary muscular arteries of the lingula $(L: W a)$ in mitral stenosis.

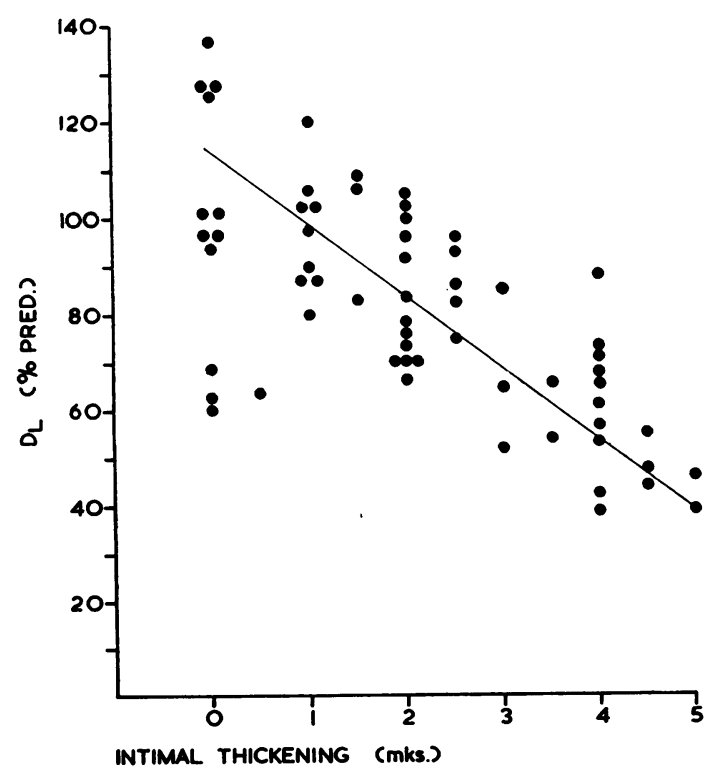

FIG. 11. Relationship between pulmonary diffusing capacity $\left(D_{\mathrm{L}}\right)$ and severity of the intimal damage in the small peripheral arteries of the lingula in mitral stenosis.

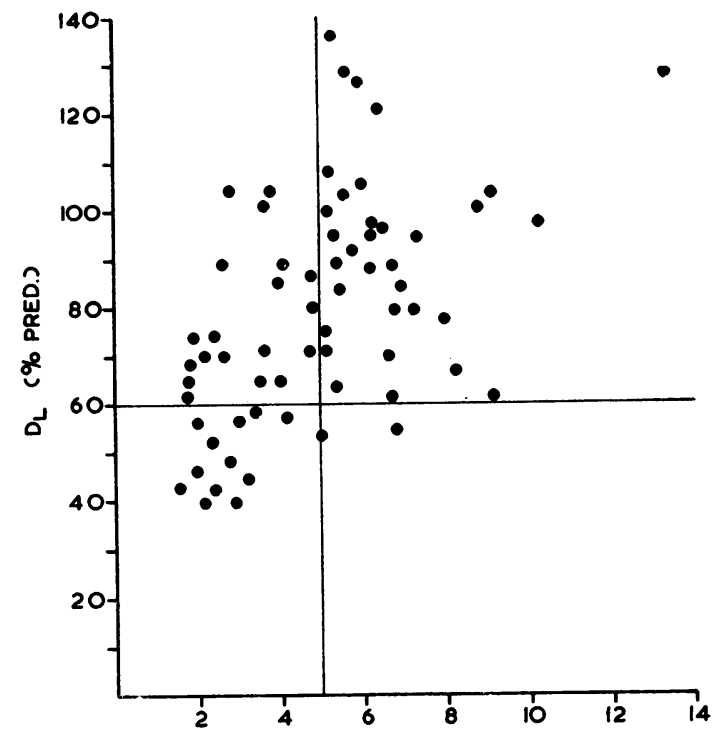

$L: W(b)$.

FIG. 10. Relationship between pulmonary diffusing capacity $(D \mathrm{~L})$ and lumen-to-wall ratio of the pulmonary arterioles of the lingula $(L: W b)$ in mitral stenosis.

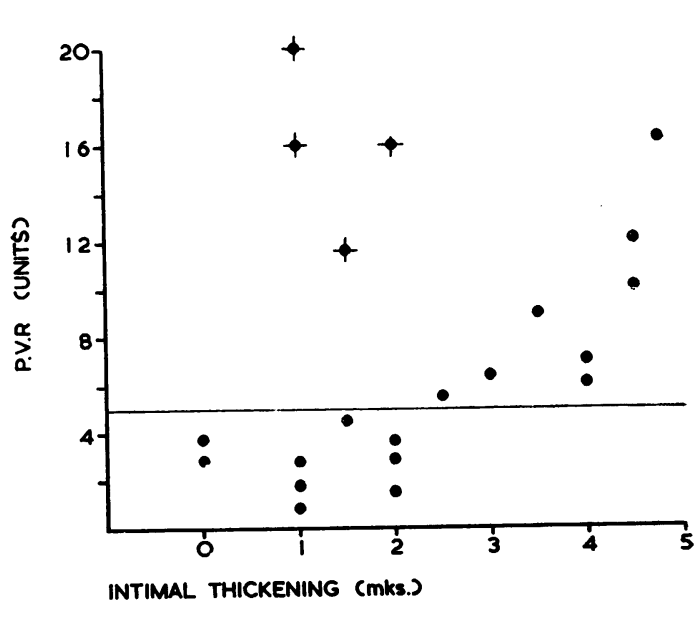

FIG. 12. Relationship between intimal damage in the $\frac{T}{0}$ small peripheral arteries of the lingula and the pulmonary $\frac{\vec{D}}{4}$ vascular resistance (P.V.R.) in mitral stenosis. + patients with high pulmonary vascular resistances whose biopsies $\stackrel{\mathbb{Q}}{\varrho}$ showed no intimal damage and who had normal diffusing capacities (Fig. 8); remainder of patients in the study 
there were four exceptions, the same four patients from group III who had proved exceptions when the relationship of the pulmonary vascular resistance to the diffusing capacity (Fig. 8) had been studied and whose biopsies showed no evidence of intimal damage in either the muscular arteries or arterioles but considerable medial thickening in the former vessels (Fig. 7).

\section{DISCUSSION}

We appreciate that since the vascular measurements were made on biopsy material from the lingula, the observed arterial lesions do not necessarily represent the true extent of this type of damage elsewhere in the lungs. In general, however, once obliterative changes are obvious in the lingular vessels, similar lesions can be expected in both lower lobes but not in the upper lobes (Harrison, 1958 ; Aber, Campbell, and Meecham, 1963).

Interpretation of the various pathological measurements in terms of disturbance of function is more speculative. The thickness of the medial coat of the pulmonary muscular arteries reflects both smooth muscle hypertrophy as well as 'spasm' in the vessel wall. Both these changes are potentially reversible (Welch, Johnson, and Zinsser, 1950 ; Clowes, Hackel, Mueller, and Gillespie, 1953 ; Harrison, 1958). Diminished lumen to wall ratios are indices of potential obstruction to blood flow through the appropriate vessels. In the pulmonary muscular arteries, this ratio reflects both medial and intimal thickening, whereas in the pulmonary arterioles, it is predominantly determined by the intimal changes. Hence, if, as occurred in several biopsies, there is considerable intimal thickening with relatively little or no medial thickening in the pulmonary muscular arteries, or alternatively, if considerable medial thickening occurs without intimal changes of any magnitude, the functional and prognostic implications of such findings would be expected to be different. We believe that intimal thickening, evaluated in the manner described, not only represents one of the factors responsible for obstruction to blood flow through the peripheral branches of the pulmonary arteries, but may also provide some measure of the degree of irreversible pulmonary vascular damage, since widespread lesions of this type are found in the lungs of patients presenting for their second mitral valvotomy despite good haemodynamic and subjective improvement after their first operation (Aber, 1962).
The present observations therefore show that in general the severity of the pulmonary vascular lesions in mitral stenosis increases as functional capacity worsens. While thickening of the media of the pulmonary muscular arteries was an almost inevitable finding, the magnitude of this change was considerably less than that in the only comparable study of this type (Heath and Whitaker, 1955). The reason for this may be that in the latter study, pulmonary arterial hypertension had been present for longer, and the pulmonary arterial pressure was on the whole considerably higher than in the present investigation. As far as is known, no previous measurements of the lumen to wall ratio of the pulmonary muscular arteries have been made in mitral stenosis. However, the observed relationship between this ratio and the grade of functional incapacity are acceptable since a similar relationship has been noted between the lumen to wall ratio of the pulmonary arterioles and functional incapacity, in both the present study and in previous work (Clowes et al., 1953 ; Enticknap, 1953). Furthermore, both these findings are likely to represent in part the cause of the progressive increase in obstruction to blood flow through the lower lobes that accompanies the development of pulmonary artery hypertension in this type of heart disease (Gorlin, Haynes, Goodale, Sawyer, Dow, and Dexter, 1951 ; Lukas and Dotter, 1952). The observed relationship between the intimal changes and functional incapacity supports this argument, since this type of lesion contributed greatly to changes in both lumen to wall ratios.

Since satisfactory transfer of carbon monoxide from the alveolar gas into the blood in the pulmonary capillaries depends on adequate ventilation and perfusion of a large number of peripheral lung units, it is not surprising to find that impairment of diffusion (as measured by the single breath carbon monoxide method) is quite common in mitral stenosis, where, as disability increases, the ventilation:perfusion balance becomes progressively more upset as the result of redistribution of blood from the lower to the upper lobes (Dollery and West, 1960; Steiner et al., 1961). Similarly, because in general the greater the functional incapacity the worse the pulmonary vascular damage, the relationships in the present study between diffusion impairment and these occlusive lesions in the peripheral branches of the pulmonary artery are as expected. Furthermore, these findings help to explain the observations of several other workers who have found a reasonably good correlation between the 
level of the pulmonary vascular resistance (and pulmonary blood flow) and diffusion in mitral stenosis (Auchincloss et al., 1959; Reid and Stevenson, 1963). On the other hand, there were three patients who had diffusing capacities within the normal range yet whose biopsies showed an appreciable degree of obliterative arterial damage. An explanation of this apparent discrepancy could be that in these patients the severity of the vascular damage in the lingula far exceeded such damage elsewhere in the lungs. A similar explanation may also be offered to account for the occasional finding of a low diffusing capacity in the absence of much intimal damage in the arterial vessels of the lingula. Alternatively, in the latter circumstances, since it was also observed that in the presence of a history of recent severe symptoms of pulmonary venous hypertension impairment of diffusion was common, alveolar capillary membrane 'damage' may also contribute to impairment of gas transfer in the lungs of such patients by causing a further disturbance of the ventilation:perfusion balance (Dollery and Hugh-Jones, 1963).

It is noteworthy that occasionally patients have very high pulmonary vascular resistances yet maintain relatively normal diffusing capacities and present little in the way of intimal thickening in the small branches of their pulmonary arteries. These patients might still be expected to gain maximum long-term benefit from a successful mitral valvotomy. They would certainly be better surgical risks than patients with similar haemodynamic disturbances, who in addition have impaired diffusing capacities and gross intimal damage within their pulmonary arterial tree (Reid and Stevenson, 1964).

Finally, a comment should be made about the six patients with relatively little disability who had diffusing capacities of $120 \%$ of predicted normal or above. This probably indicates the presence of widespread dilatation of the pulmonary capillary bed consequent upon elevation of the left atrial pressure, yet little, if any, constriction of blood flow to the lower lobes. Such conditions are only likely to exist in mitral stenosis (at rest) where the valvular obstruction is not severe.

\section{SUMMARY}

The pulmonary diffusing capacity was measured in 79 patients with dominant mitral stenosis before mitral valvotomy.

Sixty-two lingular biopsies were examined and 30 right-heart catheterizations were performed before surgery.
An attempt has been made to relate changes in the pulmonary diffusing capacity in mitral stenosis? to (1) the degree of functional incapacity, (2) the 흠 pulmonary haemodynamic disturbances, and $\frac{\bar{s}}{\sigma}$ (3) the pathological lesions in the pulmonary arterial tree of such patients.

The results indicate that impairment of diffusion usually parallels both the grade of functional incapacity and the severity of the pulmonary $\vec{\omega}$ vascular changes. If the diffusing capacity is less than $60 \%$ of predicted normal, the pulmonary $\vec{x}$ vascular resistance is usually 5 units or higher ${ }^{2}$ and there is considerable intimal thickening in the small peripheral branches of the pulmonary artery of the lingula. However, there were important $\mathcal{G}$ exceptions to this relationship, the significance of $\frac{\mathrm{O}}{\mathrm{y}}$ which is discussed.

Our thanks are due to the surgeons and physicians of the Liverpool Thoracic Surgical and Liverpool $\stackrel{\Im}{工}$ Cardiac Centres, and especially to Dr. W. S. Sutton $\vec{\bullet}$ and Dr. Colin Ogilvie for allowing us access to their of patients. We thank Dr. F. Whitwell for his advice throughout this work.

We should like to record our gratitude to the technical staff in the Respiratory and Pathology Laboratories, Broadgreen Hospital.

\section{REFERENCES}

Aber, C. P. (1962). The lungs in mitral stenosis. M.D. Thesis, Leeds

University. 18,50

Campbell, J. A., and Meecham, J. (1963). Arterial patterns in mitral stenosis. Brit. Heart J., 25, 109.

Arnott, W. M.(1963). The lungs in mitral stenosis. Brit.med.J., 2, 823. Auchincloss, J. H., Jr., Gilbert, R., and Eich, R. H. (1959). The pulmonary diffusing capacity in congenital and rheumatic heart $\times$ disease. Circulation, 19,232.

Carroll, D., Cohn, J. E., and Riley, R. L. (1953). Pulmonary function in mitral valvular disease : Distribution and diffusion characteristics in resting patients. J. clin. Invest., 32, 510 .

Clowes, G. H. A., Hackel, D. B., Mueller, R. P., and Gillespie, D. G. Оิ (1953). Relationship of pulmonary function and pathological changes in mitral stenosis. Arch. Surg., 67, 244.

Curti, P. C., Cohen, G., Castleman, B., Scannell, J. G., Friedlich, 음 A. L., and Myers, G. S. (1953). Respiratory and circulatory studies of patients with mitral stenosis. Circulation, 8, 893.

Davies, L. G., Goodwin, J. F.. Steiner, R. E., and Van Leuven, B. D. C (1953). The clinical and radiological assessment of the pulmonary arterial pressure in mitral stenosis. B*it. Heart $J ., 15,393$.

Dollery, C. T. and Hugh-Jones, P. (1963). Distribution of gas and $\mathrm{N}$ blood in the lungs in disease. Brit. med. Bull., 19, 59.

and West, J. B. (1960). Regional uptake of radioactive oxygen, $N$ carbon monoxide and carbon dioxide in the lungs of patients with mitral stenosis. Circulat. Res.,8,765.

Enticknap, J. B. (1953). Lung biopsy in mitral stenosis. J. clin. Path. $\omega$ 6, 84.

Evans, W., and Short, D. S. (1957). Pulmonary hypertension in mitral stenosis. Brit. Heart J., 19, 457.

Finley, T. N., Swenson, E. W., and Comroe, J. H., Jr. (1962). The cause of arterial hypoxemia at rest in patients with "alveolar- $\mathscr{D}$ capillary block syndrome". J. clin. Invest., 41, 618 .

Frank, R. N., Cugell, D. W., Gaensler, E. A., and Ellis, L. B. (1953). T Ventilatory studies in mitral stenosis. - a comparison with findings in primary pulmonary disease. Amer. J. Med., 15, 60 .

Friedman, B. L., de J. Macias, J., and Yu, P. N. (1959). Pulmonary function studies in patients with mitral stenosis. Amer. Rev. Tuberc., 79, 265

Gorlin, R., Haynes, F. W., Goodale, W. T., Sawyer, C. G., Dow, ® J. W., and Dexter, L.(1951). Studies of the circulatory dynamics in mitral stenosis. II. Altered dynamics at rest. Amer. Heart $J$. 41, 30 . 
Gough, J. (1955). Correlation of radiological and pathological changes in some diseases of the lung. Lancet, 1,161 .

Harrison, C. V. (1958). The pathology of the pulmonary vessels in pulmonary hypertension. Brit. J. Radiol., 31, 217.

Heath, D., and Whitaker, W. (1955). The pulmonary vessels in mitral stenosis. J. Path. Bact., 70, 291.

Hellems, H. K., Haynes, F. W., Dexter, L., and Kinney, T. D. (1948). Pulmonary capillary pressure in animals estimated by venous and arterial catheterization. Amer. J. Physiol., 155, 98.

Kernohan, J. W., Anderson, E. W., and Keith, N. M. (1929). The arterioles in cases of hypertension. Arch. intern. Med., 44, 395.

Lukas, D.S., and Dotter, C.T.(1952). Modifications of the pulmonary circulation in mitral stenosis. Amer. J. Med., 12, 639.

McIlroy, M. B., and Apthorp, G. H. (1958). Pulmonary function in pulmonary hypertension. Brit. Heart J., $20,397$.

Marshall, R., McIlroy, M. B., and Christie, R. V.(1954). The work of breathing in mitral stenosis. Clin. Sci., 13, 137.

Ogilvie, C. M., Forster, R. E., Blakemore, W. S., and Morton, J. W. (1957). A standardized breath holding technique for the clinical measurement of the diffusing capacity of the lung for carbon monoxide. J. clin. Invest., 36, 1 .

Reid, J. M., and Stevenson, J. G. (1963). Pulmonary diffusing capacity in mitral valve disease. Brit. Heart J., 25, 741.
(1964). The pulmonary diffusing capacity and ventilatory capacity before and after mitral valvotomy. Ibid., 26, 649 .

Short, D. S. (1957). The arterial bed of the lung in pulmonary hypertension. Lancet, $2,12$.

Simon, M. (1958). The pulmonary veins in mitral stenosis. J. Fac. Radiol. (Lond.), 9, 25.

Steiner, R. E., Harrison, C. V., and Goodwin, J. F. (1961). Radiological assessment of pulmonary arterial and pulmonary venous pressure. In Problems of Pulmonary Circulation [Ciba Foundation Study Group No. 8], p. 2. Churchill, London.

Turino, G. M., and Fishman, A. P. (1959). The congested lung. J. chron. Dis., 9, 510.

Weiner, R. S., and Cooper, P. (1956). Measurement of functional residual capacity-a comparison of two closed-circuit heliumresidual capacity-a comparison of two closed
dilution methods. Amer. Rev. Tuberc., 74, 729.

Welch, K. J., Johnson, J., and Zinsser, H. (1950). The significance of pulmonary vascular lesions in the selection of patients for mitral valve surgery. Ann. Surg., 132, 1027.

Williams, M. H. (1953). Pulmonary function studies in mitral stenosis before and after commissurotomy. J. clin. Invest., 32, 1094 .

Williams, R., and Hugh-Jones, P. (1960). The significance of lung function changes in asbestosis. Thorax, 15, 109. 